\title{
Knowledge and Attitude toward Epilepsy of Close Family Members of People with Epilepsy in North of Iran
}

\author{
Narges Karimi ${ }^{1}$ and Seyyed Ali Akbarian ${ }^{2}$ \\ ${ }^{1}$ Department of Neurology, School of Medicine, Immunogenetics Research Center, Clinical Research Development Unit of \\ Bou Ali Sina Hospital, Mazandaran University of Medical Sciences, Sari, Iran \\ ${ }^{2}$ Department of Emergency Medicine, School of Medicine, Mazandaran University of Medical Sciences, Sari, Iran
}

Correspondence should be addressed to Narges Karimi; drkarimi_236@yahoo.com

Received 1 August 2016; Revised 9 October 2016; Accepted 7 December 2016

Academic Editor: Louis Lemieux

Copyright (C) 2016 N. Karimi and S. A. Akbarian. This is an open access article distributed under the Creative Commons Attribution License, which permits unrestricted use, distribution, and reproduction in any medium, provided the original work is properly cited.

\begin{abstract}
Background. Knowledge and attitudes are required for relatives of people with epilepsy to allow them to better understand and cope with this condition. This study evaluated the knowledge and attitudes of family members of people with epilepsy about the disease. Methods. This cross-sectional survey was conducted using a self-administered questionnaire completed by close family members of people with epilepsy at the outpatient clinic of a medical university. The questionnaire included 25 items that determined the demographics and information on the level of knowledge and attitudes about epilepsy. Results. The 124 participants had an average age of $36.88 \pm 10.68$ years. The mean knowledge score was $10.32 \pm 2.25$ (range: 4 to 15 ). $87.1 \%$ of respondents answered that epilepsy is a brain disorder, $39(31.5 \%)$ said epilepsy is inherited. As a whole, $62(50 \%)$ had good knowledge about the disease. The mean score of attitude was $7.25 \pm 1.54$ (range: 2 to 10). $83.9 \%$ of respondents believed that a person with epilepsy can get married and get pregnant (76.6\%). Overall, 15 (12.1\%) had negative attitudes and $109(87.9 \%)$ had positive attitudes. Conclusion. The main findings of this study indicated good knowledge and a positive attitude about epilepsy among family members of people with epilepsy.
\end{abstract}

\section{Introduction}

Epilepsy is a common neurological condition that affects personal and familial behavior and social support $[1,2]$. About 50 million people worldwide suffer from epilepsy and the prevalence of active epilepsy in developing countries is 5 to 10 per 100 persons [3]. A prevalence of $0.7-1.8 \%$ has been reported in Iran [4]. Individuals with epilepsy may suffer from psychological issues such as depression, anxiety, and psychosis [5]. Accordingly, living with a person with epilepsy will provide some challenges, particularly at home. Studies have reported that relatives of people with epilepsy have an increased risk of anxiety [6]. Epilepsy can inflict an enormous burden on both the people with epilepsy (PWE) and their family caregivers, decreasing their quality of life and daily efficiency [7]. Awareness, knowledge, and attitudes are important qualities for relatives of people with epilepsy to better understand this condition [8]. Studies have shown that people with less awareness and knowledge about epilepsy tend to have negative attitudes toward the disease and misperceptions such as epilepsy being a form of insanity, untreatable, contagious, and hereditary or a form of mental retardation [9-12]. Cultural beliefs, superstition, and lack of information about epilepsy have perpetuated such misconceptions in developing countries [13-16].

Several factors about people with epilepsy and their caregivers influence the quality of life of patients. These include social disadvantages, family circumstances, seizure frequency, and severity and rate of response to treatment [17]. Studies have demonstrated that people with epilepsy and their relatives do not have adequate basic information about epilepsy including seizure precipitants, types of seizures, and side effects of medications [18]. Misunderstandings and misinformation should be recognized and corrected for optimal care. In Iran, few studies regarding knowledge of people living with epilepsy and their relatives about epilepsy were conducted.

One study in Iran reported that knowledge about epilepsy of relatives of PWE was poor and they tended to have a negative attitude toward the disease [19]. The present study 
evaluated the level of knowledge and attitudes of family members of people living with epilepsy about the disease.

\section{Methodology}

This cross-sectional survey was conducted using a selfadministered questionnaire completed by adult family members of people with epilepsy at an outpatient clinic of a medical university (Tooba clinic) in Mazandaran province in the city of Sari in northern Iran. The patients have been referred to the clinic from all urban or rural regions of Mazandaran province. This clinic is a tertiary referral center. Approximately 250 neurological patients are seen at the clinic daily.

The participants were the relatives of people with epilepsy who had a close relationship with the patient, lived in the same house, and had heard of epilepsy. The participants were interviewed at the Neurology Outpatient Clinic during patient visits. The respondents included the mothers, fathers, brothers, sisters, or the husband/wife of patients that were over 15 years of age. Iran is a Muslim country with Islamic customs. The populations of Mazandaran province are primarily Shia Muslims.

The questionnaire comprised closed-ended questions to which the responses were either "Yes," "No," or "I do not know." The participants filled out the questionnaire at a prearranged time and location and were not obliged to hurry in their responses. The investigators waited while the questionnaire was completed to offer help if there were any questions. The data was collected from April 2014 through May 2016.

The 25 items were developed after an extensive review of the international literature [20-23]. The questions were translated into Farsi from the English version and then back-translated by psychiatrists and neurologists. Straightforwardness, accuracy, and meaning were carefully checked. A pilot study was conducted with 20 randomly selected family members of people with epilepsy on two separate occasions two weeks apart to determine the feasibility and reliability of the Farsi version of the questionnaire. The reliability of the questionnaire was tested by Cronbach's alpha which resulted in an internal consistency of 0.74 .

The questions were divided into three sections. Section 1 requested demographic information including age, gender, marital status, educational level, and occupation. Section 2 investigated the level of knowledge about epilepsy (15 items) and Section 3 explored the attitudes, perception, and beliefs of the respondents toward epilepsy (10 items). Knowledge and attitude were evaluated separately for each participant. Each correct answer was awarded one point and incorrect or "I don't know" responses were awarded scores of zero. For evaluation of total attitude and knowledge of participants, the scores were summed up for each participant. The range for knowledge was $0-15$ and for attitude was $0-10$. The knowledge score was further categorized as poor (0-5), fair (6-10), or good (11-15). The attitude score was categorized as negative $(0-5)$ or positive $(6-10)$ [21, 24-26].

This project was approved by the ethics committee of the Medical School of Mazandaran University of Medical
Sciences. The study was conducted in accordance with the Helsinki declaration on research ethics. Participation was voluntary and the responses were anonymous. After obtaining informed consent, 124 literate subjects were enrolled in the study.

The data was analyzed using SPSS version 20.0. The demographic data and epilepsy knowledge and attitude scores of close relatives were analyzed using descriptive statistics (mean, percentage, and frequency distribution). Chisquare $\left(\chi^{2}\right)$ was used to determine the association between variables and demographic data. To assess the relationships between demographic information and the knowledge and attitude scores, regression analysis was conducted. Pearson's correlation was used to determine the association between attitude and knowledge. The results were considered significant at $P<0.05$.

\section{Results}

Of the 124 participants, $35.5 \%(n=44)$ were males and $64.5 \%(n=80)$ were females. The ages ranged from 18 to 58 years with a mean of $36.88 \pm 10.68$ years. The majority $(34.7 \%)$ of subjects were $37-47$ years of age. Table 1 shows the demographic characteristics of the respondents. There were no differences between males and females regarding age distribution, educational level, or number of family members, but there were differences between gender and marital status and also occupation. The majority of females were married and unemployed.

3.1. Knowledge about Epilepsy. The mean knowledge score was $10.32 \pm 2.25$ (range: 4 to 15 ). Of the 124 participants, 4 (3.2\%) scored as having poor knowledge; 58 (46.80\%) had fair knowledge; and 62 (50\%) had good knowledge. The results are summarized in Table 2 . When asked about the cause of epilepsy, the majority of participants $(108 ; 87.1 \%)$ answered that epilepsy is a brain disorder, 39 (31.5\%) said that epilepsy is inherited, $58(46.8 \%)$ said that it is without a specific cause, $54(43.5 \%)$ said that epilepsy is a mental disorder, and also 5 (4\%) believed that it is contagious. Of the 124 responders, 10 (8.1\%) believed epilepsy to be demonic possession or of supernatural origin. In terms of knowledge about trigger factors for repeated seizures, the responses were as follows: specific foods and drinks (53.5\%), sleep deprivation (66.9\%), starvation (56.5\%), and watching TV or using the computer for a long time (66.1\%). In comparison with other disorders, $64(51.6 \%)$ of respondents said that epilepsy is more dangerous than diabetes mellitus but only 17 $(13.7 \%)$ of participants believed that epilepsy is more violent than malignant carcinoma.

To assess the relationships between demographic information and knowledge, regression analysis was conducted. A significant association was found between the knowledge score and the level of education and larger family size, but not for age, gender, marital status, or occupation.

3.2. Attitudes toward Epilepsy. The mean score for attitude was $7.25 \pm 1.54$ (range: 2 to 10 ). Of the 124 responders, 15 
TABLE 1: Demographic characteristics of the respondents $(n=124)$.

\begin{tabular}{|c|c|c|c|c|}
\hline & Male $=44(\%)$ & Female $=80(\%)$ & Total (\%) & $P$ value \\
\hline \multicolumn{5}{|l|}{ Age (years) } \\
\hline $15-25$ & $11(61.2)$ & $7(38.8)$ & $18(14.5)$ & \multirow{4}{*}{0.51} \\
\hline $26-36$ & $11(26.2)$ & $31(73.8)$ & $42(33.9)$ & \\
\hline $37-47$ & $13(30.24)$ & $30(69.76)$ & $43(34.7)$ & \\
\hline$\geq 48$ & $9(42.9)$ & $12(57.1)$ & $21(16.9)$ & \\
\hline \multicolumn{5}{|l|}{ Marital status } \\
\hline Single & $16(57.14)$ & $12(42.86)$ & $28(22.6)$ & \multirow{2}{*}{0.007} \\
\hline Married & $28(29.16)$ & $68(70.84)$ & $96(77.4)$ & \\
\hline \multicolumn{5}{|l|}{ Educational level } \\
\hline Under diploma & $10(21.73)$ & $36(78.27)$ & $46(37.09)$ & \multirow{3}{*}{0.134} \\
\hline Diploma & $19(41.31)$ & $27(58.69)$ & $46(37.09)$ & \\
\hline University education & $15(46.87)$ & $17(53.13)$ & $32(25.91)$ & \\
\hline \multicolumn{5}{|c|}{ Number of members in family } \\
\hline Small $(<3)$ & $9(31.04)$ & $20(68.96)$ & $29(23.4)$ & \multirow{3}{*}{0.39} \\
\hline Average (3-5) & $30(40)$ & $45(60)$ & $75(60.5)$ & \\
\hline $\operatorname{Big}(>5)$ & $5(25)$ & $15(75)$ & $20(16.1)$ & \\
\hline \multicolumn{5}{|l|}{ Occupation } \\
\hline Employed & $11(64.71)$ & $6(35.29)$ & $17(13.73)$ & \multirow{3}{*}{0.0001} \\
\hline Unemployed & $33(63.47)$ & $19(36.53)$ & $52(41.92)$ & \\
\hline Housewife & 0 & $55(100)$ & $55(45.35)$ & \\
\hline
\end{tabular}

TABLE 2: Responses to questions on knowledge of epilepsy.

\begin{tabular}{|c|c|c|c|}
\hline Questions & Yes $\%$ & No $\%$ & Don't Know \% \\
\hline (1) Epilepsy is a hereditary disorder & 31.5 & 66.9 & 1.6 \\
\hline (2) Epilepsy is a disorder of the brain & 87.1 & 12.1 & 0.8 \\
\hline (3) The cause of epilepsy is unknown & 46.8 & 51.6 & 1.6 \\
\hline $\begin{array}{l}\text { (4) Epilepsy is caused by demon possession or } \\
\text { supernatural powers }\end{array}$ & 8.1 & 88.7 & 3.2 \\
\hline (5) Malnutrition is the cause of epilepsy & 33.1 & 65.3 & 1.6 \\
\hline (6) Epilepsy is an infectious disease and contagious & 4 & 96 & 0.0 \\
\hline (7) Epilepsy is a form of mental illness & 43.6 & 54.8 & 1.6 \\
\hline $\begin{array}{l}\text { (8) Starvation can cause attacks of seizure in epileptic } \\
\text { patients }\end{array}$ & 56.5 & 43.5 & 0.0 \\
\hline $\begin{array}{l}\text { (9) Inadequate sleep can cause attacks of seizure in } \\
\text { PWE }\end{array}$ & 66.1 & 31.5 & 1.6 \\
\hline (10) Some certain foods or drinks make a seizure & 53.2 & 44.4 & 2.4 \\
\hline $\begin{array}{l}\text { (11) Looking at the TV or computer for a long time is } \\
\text { caused of epileptic attacks }\end{array}$ & 66.1 & 32.3 & 1.6 \\
\hline \multicolumn{4}{|l|}{ (12) Epilepsy is more violent than } \\
\hline (i) Diabetes mellitus & 51.6 & 46 & 2.4 \\
\hline (ii) AIDS & 24.2 & 73.4 & 2.4 \\
\hline (iii) Malignant carcinoma & 13.7 & 83.1 & 3.2 \\
\hline (iv) Stroke & 26.6 & 72.6 & 0.8 \\
\hline
\end{tabular}

(12.1\%) had negative attitudes and 109 (87.9\%) had positive attitudes. The results are summarized in Table 3. The majority of responders, 109 (83.9\%), believed that a person with epilepsy can get married and get pregnant $(76.6 \%)$. One hundred and four $(83.9 \%)$ of the 124 respondents said PWE can have a collage education while thirty-one $(25 \%)$ believed PWE have lower intelligence than other people. Three $(2.4 \%)$ of respondents believed that PWE are insane and $9(7.3 \%)$ of participants believed that magic and religious practices improve epilepsy. In terms of treatment, 74 (59.7\%) of respondents believed that PWE require lifelong treatment. Sixty-three $(50.8 \%)$ believed that it is safe for people with 
TABLE 3: Responses to questions related to attitudes toward epilepsy.

\begin{tabular}{|c|c|c|c|}
\hline Questions & Yes $\%$ & No $\%$ & Don’t Know \% \\
\hline $\begin{array}{l}\text { (1) It is possible for a person with epilepsy to get } \\
\text { married }\end{array}$ & 83.9 & 15.3 & 0.8 \\
\hline (2) PWE can get pregnant & 76.6 & 21.8 & 1.6 \\
\hline (3) PWE can drive safely & 50.8 & 47.6 & 1.6 \\
\hline (4) PWE can swim & 54.8 & 44.4 & 0.8 \\
\hline $\begin{array}{l}\text { (5) PWE can get opportunities of appropriate } \\
\text { occupation }\end{array}$ & 77.4 & 22.6 & 0.0 \\
\hline (6) PWE require lifelong treatment & 59.7 & 40.3 & 0.0 \\
\hline (7) PWE can have a collage education & 83.9 & 15.3 & 0.8 \\
\hline (8) PWE are insane & 2.4 & 97.6 & 0.0 \\
\hline (9) PWE have lower intelligence than other people & 25 & 74.2 & 0.8 \\
\hline (10) Cure is achievable by magic/religious practices & 7.3 & 92.7 & 0.0 \\
\hline
\end{tabular}

PWE: people with epilepsy.

epilepsy to drive and 68 (54.8\%) believed that they can swim. Regression analysis showed a significant association between a positive attitude score and the female gender and level of education but no association with age, marital status, or occupation.

3.3. Correlation of Knowledge and Attitude toward Epilepsy. $64(61.5 \%)$ of the 83 respondents who said "epilepsy is not hereditary" believed that people with epilepsy can marry. There was significant difference among this groups $(P=$ $0.014)$.

Of the 68 respondents who thought "epilepsy is not a form of mental illness," 66 (97.05\%) believed people with epilepsy are not insane $(P=0.1), 57(86.36 \%)$ of respondents believed persons with epilepsy can get opportunities of appropriate occupation $(P=0.017)$, and also $60(88.23 \%)$ said persons with epilepsy can have university education (0.039). Of the 110 respondents who said "epilepsy is not caused by demon possession," 106 (92.2\%) of them believed that religious practices are not effective in improvement of epilepsy (0.0001).

As a whole, in terms of relationship between knowledge and attitude toward epilepsy, there was no significant difference between knowledge and attitude.

\section{Discussion}

This study assessed the levels of knowledge and attitudes about epilepsy of close family members of people with epilepsy. Although most people with epilepsy manage their disease on their own, family members play an important role in the follow-up and treatment of patients. The care of people with epilepsy is emotionally overwhelming and relatives are at an increased risk for depression [27]. Few studies have been done in developing countries, especially Iran, on the knowledge and attitudes of relatives of people with epilepsy about epilepsy. The present study showed that close family members of people with epilepsy had strong conceptions and good knowledge about epilepsy. They believed that epilepsy is a brain disorder $(87.1 \%)$ or an infectious disease or contagious
(96\%) and is not of supernatural origin (88.7\%). They had less information about triggers of epilepsy. Overall attitudes toward epilepsy among family members were positive. Most respondents believed PWE can marry, hold an appropriate occupation, receive university education, and are as intelligent as nonepileptics. These findings are similar to results of studies among school teachers in Iran [4] and in the UK [28]. Nevertheless, there were negative attitudes in some aspects. One less than positive finding was that persons with epilepsy can swim and drive safely. Singh and Arora found that the majority of people believed that PWE should not swim or drive [20]. The results of the present study suggest that this erroneous belief can be dangerous for the patient and other people. Religious and cultural beliefs influence the treatment and follow-up of persons with epilepsy. In the present study, $8.1 \%$ of respondents believed that epilepsy is of supernatural origin and $7.7 \%$ believed epileptic patients can be cured by magic/religious practices. Masoud and Kochaki found that $14.4 \%$ of respondents believed religious practices can affect the treatment of people with epilepsy [19]. The respondents of the present study also reported supernatural origins as the cause of epilepsy, but this is much lower than other studies and this is a positive finding of our study $[20,29,30]$. In Iran few studies about knowledge of epilepsy in different population groups including teachers, people with epilepsy, general public, and relatives were conducted $[4,19,31-33]$. These studies have shown different results. A previous study in Iran found that knowledge about epilepsy of family members of patients was poor and relatives lacked information about the disease [19]. Also survey on stigma and discrimination experienced by persons with epilepsy in Tehran revealed a moderate level of stigma experiences [33]. Another study in Iran reported poor knowledge of epilepsy and that patients with the disease were thought to have compromised mental health [34]. On the other hand, other studies in between different ethnic groups and school's teachers in Iran indicated that the level of awareness about epilepsy was quite high and teachers had positive attitude about epilepsy [4, 31]. Public awareness of epilepsy in Iran showed similar to studies conducted in high income western 
countries [32]. There was a significant association between an increase in knowledge score and an increase in family size and educational level in the present study that correlates with the findings of other studies $[29,34]$. A higher level of education and larger family size correlated with a higher percentage of correct responses to the knowledge questions. This result is consistent with findings of other study [32]. A relationship was found between increased level of education and the female gender with attitudes about epilepsy. Sidig et al. reported that $26 \%$ of respondents had good knowledge and $43 \%$ had poor knowledge about epilepsy [30], while, in the present study, only $3.3 \%$ of participants showed poor knowledge. In the present study, there was no significant association between attitude and knowledge. Saengsuwan et al. reported a weak and negative correlation between knowledge and attitude toward epilepsy [29]. This finding is different from other studies who found good knowledge to be correlated with more positive attitudes $[8,35]$.

\section{Conclusion}

The results of the present study showed that family members of PWE have a high level of knowledge and positive attitude about most aspects of epilepsy. They mostly underlined physical causes of epilepsy and rejected demon possession or supernatural powers which is a metaphysical cause. They had a positive attitude about getting an appropriate occupation and to get married. With respect to their attitudes toward the treatment of epilepsy, one-half of the interviewees believed PWE require lifelong treatment. They also declined spiritual healing as method of treatment for epilepsy. Insufficient information and incorrect beliefs about some issues related to epilepsy remain, however. Almost one-half of respondents thought epilepsy is a form of mental illness and also PWE can drive or swim safely. Family members and relatives require more education and training about epilepsy through community education programs to ameliorate misconceptions and increase understanding about this disease.

\section{Disclosure}

This study was Dr. Seyyed Ali Akbarian's dissertation doctorate towards the graduation of general medicine.

\section{Competing Interests}

The authors declare that there is no conflict of interests regarding the publication of this paper.

\section{Acknowledgments}

This study was supported by Mazandaran University of Medical Sciences (Research Project no. 322). The authors would like to appreciate the Vice Chancellor of Research and Technology of Mazandaran University of Medical Sciences for approval and supporting this study. They wish to thank all the respondents who took the time and complete the questionnaires. They also appreciate all colleagues of Department of Neurology for their assistance in collecting samples.

\section{References}

[1] R. Koul, S. Razdan, and A. Motta, "Prevalence and pattern of epilepsy (Lath/Mirgi/Laran) in rural Kashmir, India," Epilepsia, vol. 29, no. 2, pp. 116-122, 1988.

[2] R. Kobau and P. Price, "Knowledge of epilepsy and familiarity with this disorder in the U.S. population: results from the 2002 healthstyles survey," Epilepsia, vol. 44, no. 11, pp. 1449-1454, 2003.

[3] B. C. Ekeh and U. E. Ekrikpo, "The knowledge, attitude, and perception towards epilepsy amongst medical students in Uyo, Southern Nigeria," Advances in Medicine, vol. 2015, Article ID 876135, 6 pages, 2015.

[4] N. Karimi and M. Heidari, "Knowledge and attitudes toward epilepsy among school teachers in West of Iran," Iranian Journal of Neurology, vol. 14, no. 3, pp. 130-135, 2015.

[5] J. U. Ohaeri, A. W. Awadalla, and A. A. Farah, "Quality of life in people with epilepsy and their family caregivers. An Arab experience using the short version of the World Health Organization quality of life instrument," Saudi Medical Journal, vol. 30, no. 10, pp. 1328-1335, 2009.

[6] C. E. Begley, M. Famulari, J. F. Annegers et al., "The cost of epilepsy in the United States: an estimate from populationbased clinical and survey data," Epilepsia, vol. 41, no. 3, pp. 342351, 2000.

[7] M. Shafiq, M. Tanwir, A. Tariq et al., "Epilepsy: public knowledge and attitude in a slum area of Karachi, Pakistan," Seizure, vol. 16, no. 4, pp. 330-337, 2007.

[8] M. Saengpattrachai, D. Srinualta, N. Lorlertratna, E. Pradermduzzadeeporn, and F. Poonpol, "Public familiarity with, knowledge of, and predictors of negative attitudes toward epilepsy in Thailand," Epilepsy and Behavior, vol. 17, no. 4, pp. 497-505, 2010

[9] S. S. Hasan, W. W. G. Wei, K. Ahmadi, I. S. Ahmed, A. K. S. Yong, and M. Anwar, "Knowledge and attitudes toward epilepsy among Malaysian Chinese," International Journal of Collaborative Research on Internal Medicine and Public Health, vol. 2, no. 11, pp. 361-376, 2010.

[10] M.-K. Kim, I.-K. Kim, B.-C. Kim, K.-H. Cho, S.-J. Kim, and J.D. Moon, "Positive trends of public attitudes toward epilepsy after public education campaign among rural Korean residents," Journal of Korean Medical Science, vol. 18, no. 2, pp. 248-254, 2003.

[11] J. Spatt, G. Bauer, C. Baumgartner et al., "Predictors for negative attitudes toward subjects with epilepsy: a representative survey in the general public in Austria," Epilepsia, vol. 46, no. 5, pp. 736-742, 2005

[12] L. Jilek-Aall, M. Jilek, J. Kaaya, L. Mkombachepa, and K. Hillary, "Psychosocial study of epilepsy in Africa," Social Science and Medicine, vol. 45, no. 5, pp. 783-795, 1997.

[13] C. T. Tan and S. H. Lim, "Epilepsy in South East Asia," Neurological Journal of South East Asia, vol. 2, pp. 11-15, 1997.

[14] U. Seneviratne, P. Rajapakse, R. Pathirana, and T. Seetha, "Knowledge, attitude, and practice of epilepsy in rural Sri Lanka," Seizure, vol. 11, no. 1, pp. 40-43, 2002.

[15] A. F. Ab Rahman, "Awareness and knowledge of epilepsy among students in a Malaysian University," Seizure, vol. 14, no. 8, pp. 593-596, 2005.

[16] M. Bishop and C. Allen, "Coping with epilepsy: research and intervention," in Coping with Chronic Illness and Disability: Theoretical, Empirical and Clinical Aspect, pp. 241-266, Springer, New York, NY, USA, 2007. 
[17] P. L. Lua, K. Nor-Khaira-Wahida, A. A. Zariah, and K. F. Lee, "Caregiving for epilepsy: awareness, knowledge, attitude and health-related quality of life of family caregivers," Malaysian Journal of Psychiatry, vol. 23, no. 1, 2014, MJP-01-05-14.

[18] J. W. Wheless, "Intractable epilepsy: a survey of patients and caregivers," Epilepsy and Behavior, vol. 8, no. 4, pp. 756-764, 2006.

[19] S. A. Masoud and E. Kochaki, "Surveying the family attitude of a patients with epilepsy hospitalized in Shahid Beheshti Hospital in Kashan, 1999-2000," Journal of Kashan University of Medical Sciences, vol. 8, no. 1, pp. 79-86, 1999.

[20] A. Singh and A. K. Arora, "Knowledge, attitude and practices of relatives of epileptic towards epilepsy," Nursing and Midwifery Research Journal, vol. 1, no. 2, pp. 77-81, 2005.

[21] M. Kabir, Z. Iliyasu, S. Abubakar, Z. S. Kabir, and A. U. Farinyaro, "Knowledge, attitude and beliefs about epilepsy among adults in a northern Nigerian urban community," Annals of African Medicine, vol. 4, no. 3, pp. 107-112, 2005.

[22] A. F. Mustapha, O. O. Odu, and O. Akande, "Knowledge, attitudes and perceptions of epilepsy among secondary school teachers in Osogbo South-West Nigeria: a community based study," Nigerian Journal of Clinical Practice, vol. 16, no. 1, pp. 1218, 2013.

[23] M. G. Devi, V. Singh, and K. Bala, "Knowledge, attitude and practices among patients of epilepsy attending tertiary hospital in Delhi, India and a review of Indian studies," Neurology Asia, vol. 15, no. 3, pp. 225-232, 2010.

[24] L. F. Owolabi, N. M. Shehu, and S. D. Owolabi, "Epilepsy and education in developing countries: a survey of school teachers' knowledge about epilepsy and their attitude towards students with epilepsy in Northwestern Nigeria," Pan African Medical Journal, vol. 18, p. 255, 2014.

[25] B. Thanavanh, M. Harun-Or-Rashid, H. Kasuya, and J. Sakamoto, "Knowledge, attitudes and practices regarding HIV/ AIDS among male high school students in Lao People's Democratic Republic," Journal of the International AIDS Society, vol. 16, Article ID 17387, 2013.

[26] Y. Shiferaw, A. Alemu, A. Girma et al., "Assessment of knowledge, attitude and risk behaviors towards HIV/AIDS and other sexual transmitted infection among preparatory students of Gondar town, north west Ethiopia," BMC Research Notes, vol. 4, article 505, 2011.

[27] J. Elliott and B. Shneker, "Patient, caregiver, and health care practitioner knowledge of, beliefs about, and attitudes toward epilepsy," Epilepsy and Behavior, vol. 12, no. 4, pp. 547-556, 2008.

[28] L. McEwan, J. Taylor, M. Casswell et al., "Knowledge of and attitudes expressed toward epilepsy by carers of people with epilepsy: a UK perspective," Epilepsy and Behavior, vol. 11, no. 1, pp. 13-19, 2007.

[29] J. Saengsuwan, W. Laohasiriwong, S. Boonyaleepan, K. Sawanyawisuth, and S. Tiamkao, "Knowledge, attitudes, and care techniques of caregivers of PWE in northeastern Thailan," Epilepsy \& Behavior, vol. 27, no. 1, pp. 257-263, 2013.

[30] A. Sidig, G. Ibrahim, A. Hussein et al., "A study of knowledge, attitude, practice towards epilepsy among relative of epileptic patients in Khartoum State," Sudanese Journal of Public Health, vol. 4, no. 4, pp. 393-398, 2009.

[31] E. Masoudnia, "Awareness, understanding and attitudes towards epilepsy among Iranian ethnic groups," Seizure, vol. 18, no. 5, pp. 369-373, 2009.
[32] H. Ghanean, M. Nojomi, and L. Jacobsson, "Public awareness and attitudes towards epilepsy in Tehran, Iran," Global Health Action, vol. 6, p. 21618, 2013.

[33] H. Ghanean, L. Jacobsson, and M. Nojomy, "Self-perception of stigma in persons with epilepsy in Tehran, Iran," Epilepsy \& Behavior, vol. 28, no. 2, pp. 163-167, 2013.

[34] F. Behrouzian and S. Neamatpour, "Parental knowledge and mental health in parents of children with epilepsy," Pakistan Journal of Medical Sciences, vol. 26, no. 1, pp. 191-194, 2010.

[35] J. Saengsuwan, S. Boonyaleepan, J. Srijakkot, K. Sawanyawisuth, and S. Tiamkao, "Factors associated with knowledge and attitudes in persons with epilepsy," Epilepsy \& Behavior, vol. 24, no. 1, pp. 23-29, 2012. 


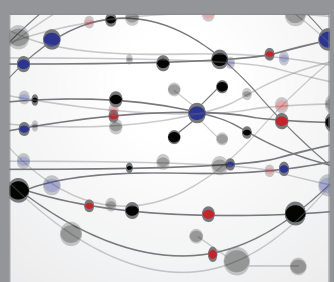

The Scientific World Journal
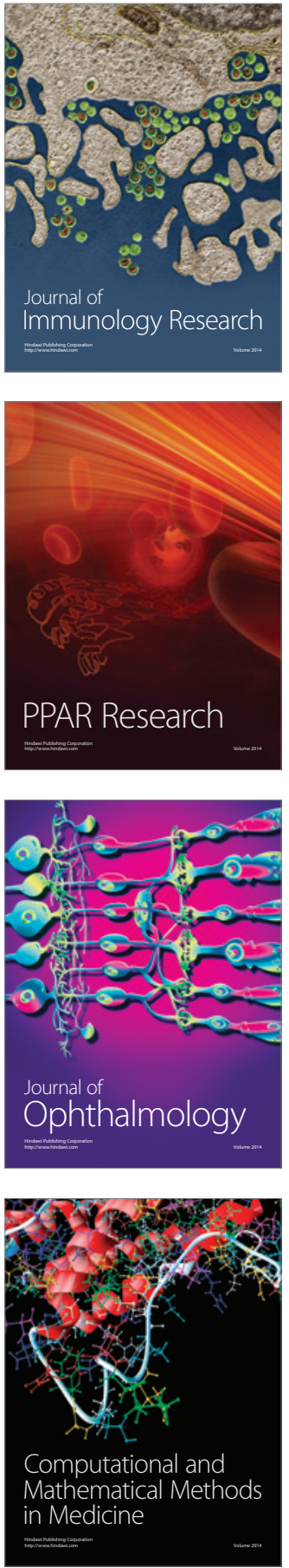

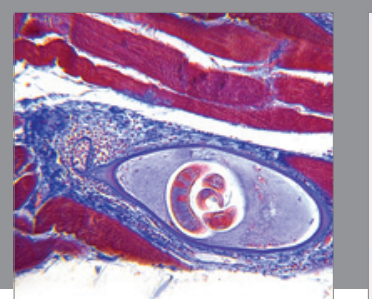

Gastroenterology Research and Practice

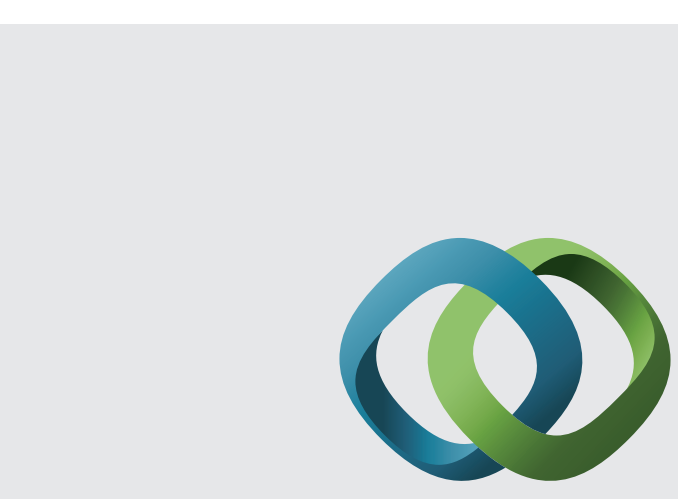

\section{Hindawi}

Submit your manuscripts at

http://www.hindawi.com
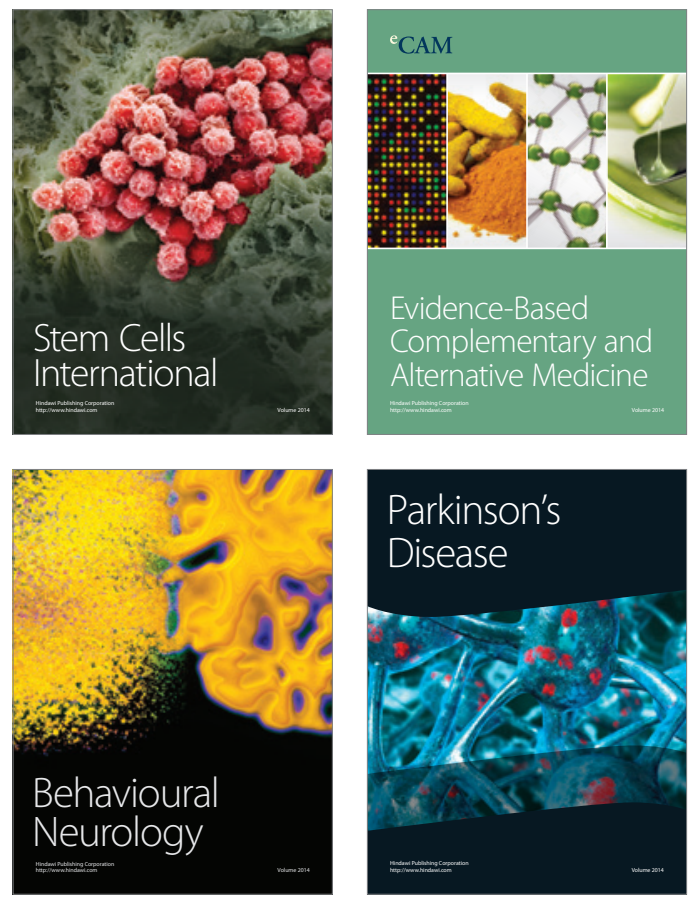
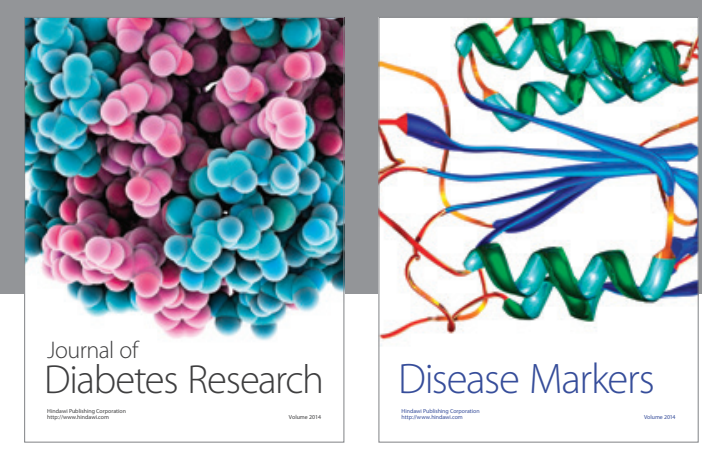

Disease Markers
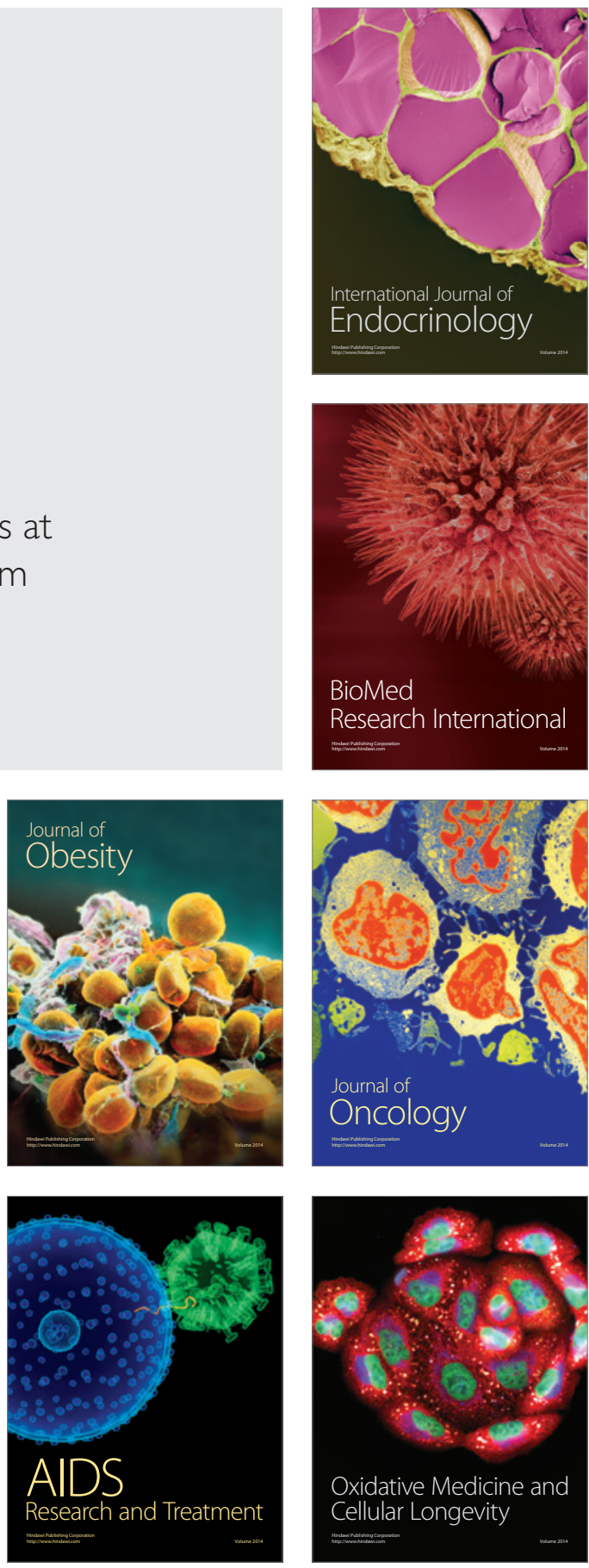